\title{
Bacterial Associates of a Desert Specialist Fungus-Growing Ant Antagonize Competitors with a Nocamycin Analog
}

Katherine A. Hansen, Rose R. Kim, Elisabeth S. Lawton, Janet Tran, Stephanie K. Lewis, Arjan S. Deol, and Ethan B. Van Arnam*

Keck Science Department of Claremont McKenna, Pitzer, and Scripps Colleges, Claremont, CA 91711, United States

*to whom correspondence should be addressed: evanarnam@kecksci.claremont.edu

\begin{abstract}
Fungus-growing ants are defended by antibiotic-producing bacterial symbionts in the genus Pseudonocardia. Nutrients provisioned by the ants support these symbionts but also invite colonization and competition from other bacteria. As an arena for chemically-mediated bacterial competition, this niche offers a window into ecological antibiotic function with well-defined competing organisms. From multiple colonies of the desert specialist ant Trachymyrmex smithi, we isolated Amycolatopsis bacteria that inhibit the growth of Pseudonocardia symbionts. Using bioassay-guided fractionation, we discovered a novel analog of the antibiotic nocamycin that is responsible for this antagonism. We identified the biosynthetic gene cluster for this antibiotic, which has a suite of oxidative enzymes consistent with this molecule's more extensive oxidative tailoring relative to similar tetramic acid antibiotics. High genetic similarity to globally distributed soil Amycolatopsis isolates suggest that this ant-derived Amycolatopsis strain may be an opportunistic soil strain whose antibiotic production allows for competition in this specialized niche. This nocamycin analog adds to the catalog of novel bioactive molecules isolated from bacterial associates of fungus-growing ants and its activity against ant symbionts represents, to our knowledge, the first documented ecological function for the widely distributed enoyl tetramic acid family of antibiotics.
\end{abstract}




\section{INTRODUCTION}

Fungus-growing ants have well-defined associations with multiple microbial partners, forming a network of interactions that is a model system for the study of symbiosis. ${ }^{1}$ Interspecies interactions throughout nature are mediated by chemical exchange, and molecular dissection of the fungus-growing ant system has offered a window into such interactions as well as a productive source of novel bioactive compounds such as the antifungals dentigerumycin, selvamicin, and cyphomycin. ${ }^{2-4}$ Among their microbial associations, fungus-growing ants cultivate a basidiomycete fungus as their primary food source, which they must defend against a specialist ascomycete fungal pathogen Escovopsis. Symbiotic Actinobacteria in the genus Pseudonocardia grow on the cuticle of these ants and produce antifungal molecules that suppress the growth of Escovopsis. ${ }^{2,5}$ These Pseudonocardia are transmitted vertically and are nourished by secretions from specialized crypts on the cuticle of these ants. ${ }^{6-8}$

Pseudonocardia isolates from fungus-growing ants are often observed to antagonize other strains of ant-associated Pseudonocardia, which are likely competitors in this niche. ${ }^{9}$ The molecular basis for this antagonism is known for Pseudonocardia from a population of the Central American ant Apterostigma dentigerum, in which a plasmid-encoded rebeccamycin antibiotic antagonizes Pseudonocardia from neighboring ant colonies. ${ }^{10}$ In a population of the North American ant Trachymyrmex septentrionalis, Pseudonocardia antagonize competitors using the thiopeptide antibiotic GE37468. ${ }^{11}$ Actinobacteria other than Pseudonocardia have been detected on the cuticle of fungus growing ants in both culture-dependent and sequencing-dependent studies, and it remains debated whether these additional bacteria are transient or instead are maintained by the ants as part of a more complex cuticular microbiome. ${ }^{12}$ Competition is expected when multiple bacterial strains co-occur in an ant population and conceptual frameworks have been developed for such bacteria-bacteria competition in the context of fungus-growing ants. ${ }^{9,13,14}$ 
Chemical defenses from bacterial symbionts of fungus-growing ants, both antibacterial and antifungal, have recently been a productive source for chemical discovery. We have turned our attention to the chemical ecology of desert-dwelling fungus-growing ants as their microbial partnerships are largely unexplored and their adaptation to a unique environment may include unique defensive compounds from their microbial associates. Over 200 species of fungusgrowing ants are found in the Neotropics and while they are best known as the ubiquitous leaf cutter ants of Central and South American rain forests, they also include several desert specialist species found in southwestern North America. ${ }^{15,16}$ Trachymyrmex smithi is one such desertadapted fungus-growing ant, found in the Chihuahuan desert from New Mexico into Northeastern Mexico. Colonies of T. smithi can exceed 1000 individuals and the ants feed their fungal cultivar with mesquite leaflets and other collected plant matter. The ants appear to have adapted to fungal cultivation in dry desert soils by placing their fungus chambers deep underground. ${ }^{16,17}$ Prior studies have noted the gray coating on the cuticle of these ants, presumed to be Actinobacteria, ${ }^{16}$ but these microbes have not previously been characterized. In this study we have focused on the chemical basis for antibacterial niche defense by bacterial associates of the ant T. smithi. We find that these ants host not just Pseudonocardia but also Actinobacteria in the genus Amycolatopsis that produce a novel analog of the antibiotic nocamycin.

\section{RESULTS AND DISCUSSION}

Collection and Microbial Isolation. We began by collecting T. smithi ants from multiple sites in Las Cruces, New Mexico in July 2017 and July 2018 and isolated Actinobacteria from the cuticle of these ants. We used established methods for culturing symbiotic Pseudonocardia from live fungus-growing ants ${ }^{18}$ and targeted our isolations to the propleural plates of these ants, a site known to house symbiotic Pseudonocardia in other Trachymyrmex ant species. ${ }^{8,12}$ This targeted bacterial isolation approach aimed to avoid culturing transient bacteria that might be present on 
the ant cuticle. Our isolations yielded not only Pseudonocardia, from 9 ant colonies, but also Actinobacteria from the closely related genus Amycolatopsis, from 5 ant colonies (Table S1).

Competition Assays. We wondered whether competition among these T. smithi-associated bacteria was mediated by antibacterial production, so we assessed competitive dynamics of a subset of our isolates, two Pseudonocardia and two Amycolatopsis, in an intruder assay (Figure 1). In this assay, an established bacterial colony on an agar plate is surrounded by an "intruder" strain of bacteria. A zone of inhibition surrounding the central colony indicates that it produces a diffusible antibacterial agent active against the intruder. ${ }^{9,10}$ Our assay indicated robust inhibition of the Pseudonocardia isolates by both Amycolatopsis isolates, and indicated that the Amycolatopsis are resistant to their own antibacterials.

\begin{tabular}{|c|c|c|c|c|}
\hline \multirow[t]{3}{*}{ A } & \multicolumn{4}{|c|}{ Intruder Strain } \\
\hline & \multicolumn{2}{|c|}{ Amycolatopsis } & \multicolumn{2}{|c|}{ Pseudonocardia } \\
\hline & 17SM-2A & 17SM-8A & $17 \mathrm{SM}-1$ & $17 \mathrm{SM}-6$ \\
\hline . $17 \mathrm{SM}-2 \mathrm{~A}$ & 0 & 0 & 3.0 & 2.4 \\
\hline 17SM-8A & 0 & 0 & 1.6 & 1.6 \\
\hline $17 \mathrm{SM}-1$ & 0 & 0 & 0 & 0 \\
\hline ๕ 17 SM- 6 & 0 & 0 & 0 & 0 \\
\hline
\end{tabular}
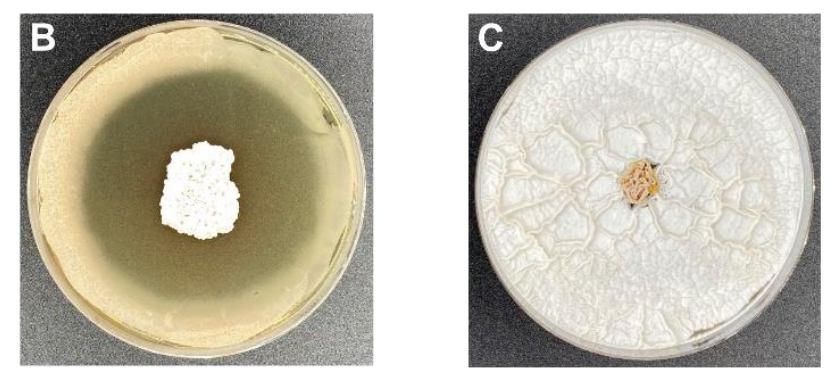

Figure 1. Intruder assay data. A. Zone of inhibition $(\mathrm{cm})$ for resident-intruder pairings. B. Pairing showing strong inhibition of Pseudonocardia 17SM-1 intruder by Amycolatopsis 17SM-2A resident. C. Pairing showing no inhibition of Amycolatopsis 17SM-2A intruder by Pseudonocardia 17SM-1 resident. 
Activity-Guided Fractionation and Structure Elucidation. To establish the molecular basis for this inhibition by the Amycolatopsis isolate with the greatest inhibitory activity, 17SM-2A, we cultured it on YMEA agar and carried out activity-guided fractionation of the ethyl acetate extract of these cultures. During fractionation we monitored antibacterial activity against the Pseudonocardia isolate 17SM-1 that was strongly inhibited in our intruder assay. Two rounds of fractionation by reversed-phase chromatography, using a C18 cartridge followed by preparative HPLC, revealed the active antibacterial molecule.

Detailed structural characterization by MS and by NMR established that the antibacterial molecule is a novel enoyl tetramic acid antibiotic, nocamycin V (Figure 2). High-resolution ESIMS ( $m / z 520.2180\left[\mathrm{M}+\mathrm{H}^{+}\right]$; calcd for $\left.\mathrm{C}_{26} \mathrm{H}_{34} \mathrm{NO}_{10}, 520.2183, \Delta 0.6 \mathrm{ppm}\right)$ supported a molecular formula with one additional oxygen relative to the known antibacterial nocamycin I. Correlations from 2D NMR experiments (COSY, HMBC, ROESY) allowed us to assign all NMR signals and establish that nocamycin $\mathrm{V}$ matches the structure of nocamycin I with the addition of a hydroxyl group at carbon 20 (Figure S2). ROESY correlations support the same stereochemistry of the bicyclic ketal ring system as for nocamycin I and our optical rotation measurement for nocamycin V is similar to that of nocamycin I, supporting the same absolute stereochemistry.

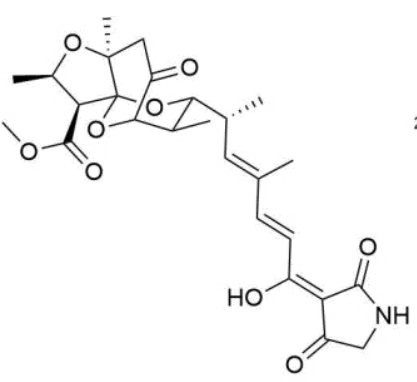

nocamycin I

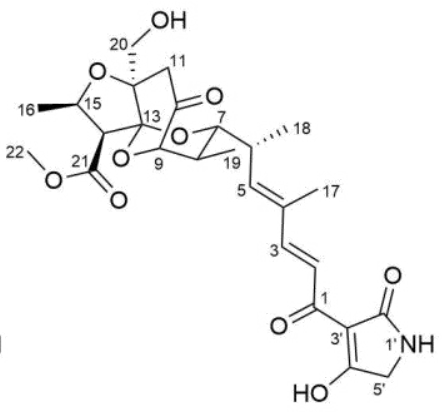

nocamycin $\mathrm{V}$

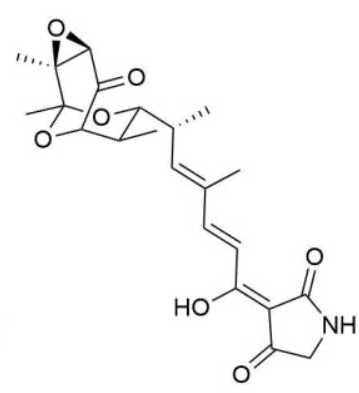

tirandamycin $\mathrm{A}$

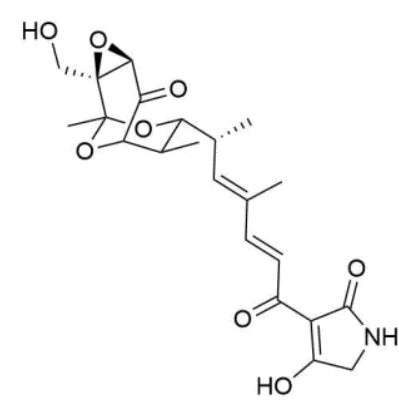

tirandamycin B

Figure 2. Select enoyl tetramic acid antibiotics. 
Our NMR data, both in $d_{4}$-methanol and in $d_{\sigma}$-DMSO, indicate that nocamycin $V$ adopts the 1-keto-4'-enol tautomer in contrast to the 1-enol-4'-keto tautomer reported for nocamycin I. Notable spectral differences for this region include the $C 1 \delta^{13} \mathrm{C}$ value for nocamycin $\mathrm{V}$ appearing 8.16 PPM downfield relative to nocamycin I ${ }^{19}$ indicating a ketone group rather than an enol. The $\delta^{13} \mathrm{C}$ values for the conjugated region of nocamycin $\mathrm{V}$ more closely match those for tirandamycin B, a related molecule that adopts the 1-keto-4'-enol tautomer, than nocamycin I (Figure 2). ${ }^{20}$ Our data also are consistent with the empirical rule for keto-enol tautomers of this conjugated system proposed by Zhen et al.: a ${ }^{1} \mathrm{H}$ chemical shift value at $\mathrm{C} 5$ of less than 6.00 PPM indicates the 1keto-4'-enol tautomer. ${ }^{20}$ The apparent influence of a distal hydroxyl group on the keto-enol equilibrium, while unexpected, appears conserved for both the tirandamycins and nocamycins.

Structurally related antibiotics include nocamycins I and II, the engineered nocamycin analogs nocamycins III and IV, streptolydigin, and the tirandamycin family of compounds, all of which contain both a cyclic ketal moiety and the dienoyl tetramic acid moiety. These compounds have activity against Gram-positive bacteria, via inhibition of bacterial RNA polymerase. ${ }^{21,22}$ Several tirandamycin compounds have demonstrated activity against vancomycin-resistant Enterococcus faecalis (VRE). For anti-VRE activity, tirandamycin B, which has the same hydroxyl placement as nocamycin $\mathrm{V}$, is approximately 40 -fold less potent than tirandamycin $A .{ }^{23}$ The tirandamycins also have anti-filarial activity against the nematode parasite Brugia malayi via inhibition of asparaginyl-tRNA synthetase (AsnRS), and for this activity tirandamycin B is more potent than tirandamycin A. ${ }^{24}$

Activity Testing. To assess the ecologically-relevant antibiotic activity of nocamycin $\mathrm{V}$, we performed agar diffusion assays using the pure compound against a panel of bacteria and fungi (Table 1). Consistent with the intruder assay data, the nocamycin V-producing isolate Amycolatopsis 17SM-2A is resistant to the compound, indicating self-resistance. Large zones of inhibition were observed for symbiotic Pseudonocardia isolates collected from $T$. smithi, from 
other Trachymyrmex from the American Southwest, and from other fungus-growing ants. This finding is consistent with Amycolatopsis 17SM-2A effectively antagonizing bacterial competitors in the fungus-growing ant niche using nocamycin V. At the concentration tested, no inhibition was observed for the ant-associated Amycolatopsis isolates, suggesting that the resistance mechanism from 17SM-2A is shared among other Amycolatopsis isolates. Consistent with the known activity for nocamycin I, nocamycin V inhibited Gram-positive bacteria but not Gramnegative bacteria. We also observed no antifungal activity against Escovopsis, the ecologicallyrelevant fungal pathogen of fungus-growing ant nests.

Table 1. Inhibitory activity of nocamycin V. Zones of inhibition are reported for $10 \mu \mathrm{g}$ nocamycin $\mathrm{V}$ in agar diffusion assays.

\begin{tabular}{lc}
\hline Organism & Zone of inhibition $\mathbf{( c m )}$ \\
\hline Amycolatopsis 17SM-2A & 0 \\
Amycolatopsis 17SM-8A & 0 \\
Amycolatopsis 18SM-2A & 0 \\
Pseudonocardia 17SM-1 & 1.1 \\
Pseudonocardia 17SM-3 & 1.6 \\
Pseudonocardia 17SM-6 & 1.0 \\
Pseudonocardia 18PO-3 & 2.2 \\
Pseudonocardia 18AZ-4 & 1.6 \\
Pseudonocardia 17SE-9 & 1.6 \\
Pseudonocardia PLR1 & 2.2 \\
Bacillus subtilis 3610 & 0 \\
Escherichia coli & 0 \\
Escovopsis sp. & 0 \\
Saccharomyces cerevisiae & 0 \\
\hline
\end{tabular}

Nocamycin V Production Screen. As our intruder assay and agar diffusion assay data suggest that nocamycin $\mathrm{V}$ production by Amycolatopsis 17SM-2A could make it an effective competitor against other ant-associated bacteria in this niche, we wondered whether this molecule is broadly distributed among bacterial associates of $T$. smithi ants. We conducted an LCMS screen of all Amycolatopsis isolates that we recovered from $T$. smithi ants during our collections 
in both 2017 and 2018, and also of our Pseudonocardia isolates from 2018 (Table 2). We detected nocamycin $\mathrm{V}$ in five out of 12 Amycolatopsis isolates; these nocamycin-containing isolates derive from three different $T$. smithi colonies and represent sampling across two years. We did not detect the compound in any of the Pseudonocardia isolates. These findings, based on our limited sampling, suggest that nocamycin-producing Amycolatopsis can effectively colonize $T$. smithi ants. We note that Amycolatopsis 17SM-8A, which also showed robust inhibition of Pseudonocardia in our intruder assay, does not produce nocamycin V. We are currently investigating other antibiotics from bacterial isolates from this niche.

Table 2. Nocamycin $V$ production from Actinobacteria isolates, as detected by LCMS.

\begin{tabular}{lcccc}
\hline \multicolumn{1}{c}{ Bacterial Isolate } & $\begin{array}{c}\text { Las Cruces, New Mexico } \\
\text { Collection Site }\end{array}$ & $\begin{array}{c}\text { Ant } \\
\text { Colony }\end{array}$ & $\begin{array}{c}\text { Collection } \\
\text { date }\end{array}$ & $\begin{array}{c}\text { Nocamycin V } \\
\text { production }\end{array}$ \\
\hline Amycolatopsis 17SM-2A & Tellbrook Park & 17 SM-2 & $07-2017$ & + \\
Amycolatopsis 17SM-2B & Tellbrook Park & 17 SM-2 & $07-2017$ & - \\
Amycolatopsis 17SM-8A & Tellbrook Park & 17 SM-8 & $07-2017$ & - \\
Amycolatopsis 17SM-8B & Tellbrook Park & $17 S M-8$ & $07-2017$ & - \\
Amycolatopsis 18SM-1 & Desert Trails Park & $18 S M-1$ & $07-2018$ & - \\
Amycolatopsis 18SM-2A & Tellbrook Park & 17 SM-8 & $07-2018$ & + \\
Amycolatopsis 18SM-2B & Tellbrook Park & $17 S M-8^{b}$ & $07-2018$ & - \\
Amycolatopsis 18SM-2C & Tellbrook Park & $17 S M-8$ & $07-2018$ & - \\
Amycolatopsis 18SM-3A & Tellbrook Park & $18 S M-3$ & $07-2018$ & + \\
Amycolatopsis 18SM-3B & Tellbrook Park & $18 S M-3$ & $07-2018$ & + \\
Amycolatopsis 18SM-3C & Tellbrook Park & $18 S M-3$ & $07-2018$ & + \\
Amycolatopsis 18SM-4 & Desert Trails Park & $18 S M-4$ & $07-2018$ & - \\
Pseudonocardia 18SM-5A & Tellbrook Park & $18 S M-5$ & $07-2018$ & - \\
Pseudonocardia 18SM-5B & Tellbrook Park & $18 S M-5$ & $07-2018$ & - \\
Pseudonocardia 18SM-6 & Desert Trails Park & $18 S M-6$ & $07-2018$ & - \\
Pseudonocardia 18SM-7 & Desert Trails Park & $18 S M-1$ & $07-2018$ & - \\
\hline
\end{tabular}

aFor multiple bacterial strains from the same ant colony, each isolate comes from a different ant

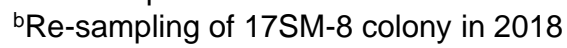


Genome and Biosynthetic Gene Cluster Analysis. We were interested in identifying the nocamycin biosynthetic gene cluster (BGC) to understand the genetic basis for the compound's unique oxidation pattern and to understand how it arrived in this unique niche. We used PacBio sequencing to obtain a complete genome for Amycolatopsis isolate 17SM-2A and identified the nocamycin V BGC using AntiSMASH v6.0. ${ }^{25}$ The nocamycins, tirandamycins, and streptolydigin consist of a hybrid PKS-NRPS scaffold elaborated through oxidative tailoring. The BGC for nocamycin I was recently characterized in the strain Saccharothrix syringae NRRL B-16468. ${ }^{26}$ As expected, the nocamycin V BGC is broadly similar with homologs present for all genes in the nocamycin I BGC (Figure 3, Table S3). The nocamycin V BGC has a distinct gene order and bears three additional genes absent in the nocamycin I BGC: these code for the putative transcriptional regulator NmvT and two putative cytochromes P450, NmvR and NmvS. In total, the nocamycin V BGC has four putative cytochromes P450, including homologs for the two P450s in the nocamycin I cluster, NmvG and NmvO.

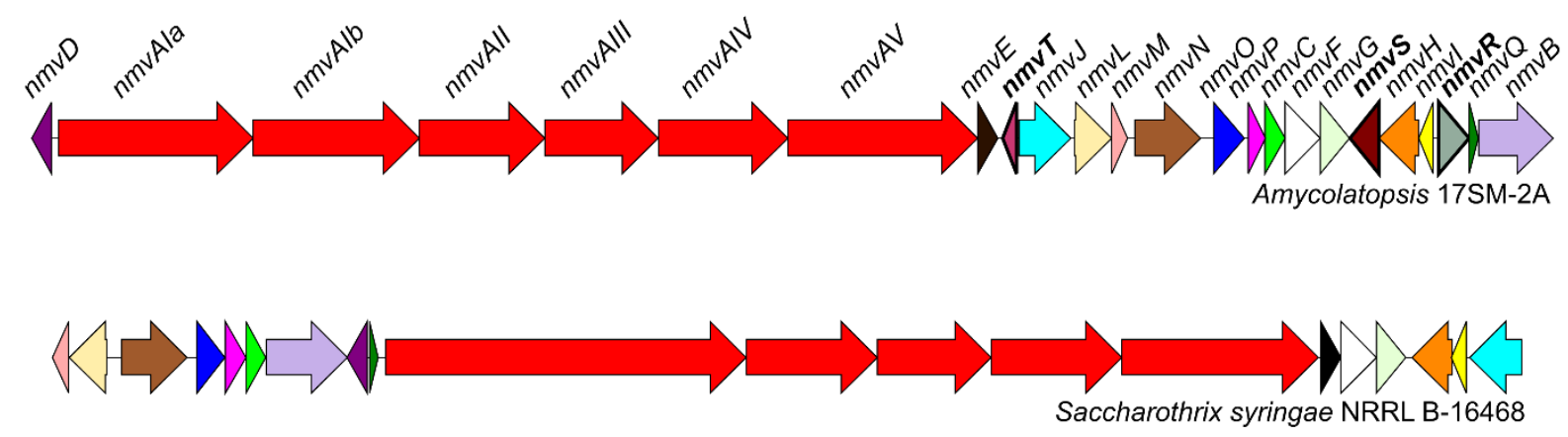

Figure 3. Biosynthetic gene clusters for nocamycin $\mathrm{V}$ (top) and nocamycin I (bottom). Color coding denotes homologous genes. Genes in bold are unique to the nocamycin V BGC.

Because nocamycin $\mathrm{V}$ bears only a single additional oxidation relative to nocamycin I-the C20 hydroxyl group-the presence of not one but two additional oxidative enzymes was unexpected. The complex oxidation patterns observed for the polycyclic ketal headgroups of the nocamycins and tirandamycins have inspired mechanistic studies to untangle the sequence of 
oxidative tailoring steps. ${ }^{19,26-30}$ Remarkably, a single cytochrome P450 enzyme, Taml, accomplishes three distinct oxidative steps as part of a cascade of oxidative reactions on the tirandamycin scaffold, resulting in installation of a hydroxyl group at $\mathrm{C} 18$, analogous to the $\mathrm{C} 20$ hydroxyl of nocamycin $\mathrm{V} .{ }^{28,29}$ From a phylogeny of cytochromes $\mathrm{P} 450$ from tirandamycin and nocamycin BGCs (Figure S5), we find that NmvR is homologous to Taml, which could indicate a role in installation of the $\mathrm{C} 20$ hydroxyl group. A complex interplay of oxidations is likely and future investigation of the biosynthesis of nocamycin $\mathrm{V}$ would contribute to our understanding of multifunctional enzymes and co-dependent oxidations.

We further examined the genome of Amycolatopsis 17-SM2A to understand the origin of this strain and the distribution of this molecule beyond this specialized niche. By searching the NCBI nucleotide databases we identified four additional strains, all Amycolatopsis with BGCs highly homologous to the nocamycin V cluster, that we predict are also producers of nocamycin V (Table S4, Figure S6). Three of these strains are from soil while one is a plant endophyte, and all share greater than 97\% 16S sequence identity with Amycolatopsis 17-SM2A. The most similar strain, Amycolatopsis keratiniphila strain $\mathrm{FH} 1893$ (isolated from a soil sample from India), shares 94.3\% average nucleotide identity with Amycolatopsis 17-SM2A across the entire genome. This extremely high similarity to soil isolates is consistent with Amycolatopsis 17-SM2A being acquired by the ants from soil with nocamycin $\mathrm{V}$ aiding its competition with symbiotic Pseudonocardia on the ants. Pseudonocardia are vertically transmitted by fungus-growing ants while nonPseudonocardia isolates from these ants are assumed to be acquired from the environment. ${ }^{12}$

Dienoyl tetramic acid antibiotics, particularly tirandamycins, are encountered with some frequency in studies of bacteria from diverse environments. Production of tirandamycins has been reported from at least 10 strains of Streptomyces of both marine and terrestrial origin. ${ }^{20,22,31,32}$ Nocamycin I has been isolated from multiple Actinobacteria: Saccharothrix syringae NRRL B16468 and Microtetraspora caesia ATCC $31295 .{ }^{33,34}$ To our knowledge, however, a niche 
competition role for nocamycin $\mathrm{V}$ is the first ecological function ascribed to an antibiotic from the dienoyl tetramic acid family.

\section{CONCLUSIONS}

Our study of an unexplored ecological niche, the microbial community of the desert-adapted fungus-growing ant $T$. smithi, has revealed a novel antibacterial compound that mediates bacterial competition. Nocamycin $\mathrm{V}$ belongs to a family of compounds of clinical interest with activity against antibiotic-resistant bacteria. It is, to our knowledge, the first enoyl tetramic acid antibiotic ascribed an ecological function and it adds to the diverse catalog of novel bioactive molecules from fungus-growing ant microbiomes. Bacterial competitors, such as this nocamycin V-producing Amycolatopsis strain that likely came from soil, further expand the roster of organisms associated with fungus-growing ants that interact using small molecules. Insect microbiomes, especially those from underexplored environments, are rich and largely untapped reservoirs of bioactive chemistry.

\section{MATERIALS AND METHODS}

General chemical analysis procedures. UV-visible absorbance spectra were collected on an Agilent 8453 spectrophotometer. High resolution mass spectrometry and MS/MS analysis was performed on a Waters Xevo G2-XS qTof mass spectrometer. LCMS analysis was performed on an Agilent 1200 series HPLC coupled to an Agilent 6120 mass spectrometer. NMR experiments were performed on a Bruker AVANCE III $500 \mathrm{MHz}$ NMR spectrometer fitted with either a broadband probe or with an inverse TXI probe. Chemical shifts were referenced to the residual solvent peak. Optical rotation was measured on a Jasco P-2000 polarimeter.

Bacterial collection and isolation. Actinobacteria were isolated from the propleural (laterocervical) plates of Trachymyrmex smithi worker ants by scraping with a sterile pick and 
plating onto chitin agar as described previously. ${ }^{18}$ Ants were collected in Las Cruces, New Mexico under permits from the city of Las Cruces. Isolate details including specific collection location, collection date, and ant species are described in Table S1.

Intruder assays. A concentrated suspension of spores $(5 \mathrm{uL})$ was spotted in the center of agar plates (YMEA 1\% agar; $25 \mathrm{~mL}$ agar per $100 \times 15 \mathrm{~mm}$ plate). The plates were incubated at $30^{\circ} \mathrm{C}$ for 7 days. A suspension of the "intruder" spores (15 uL concentrated spores in $315 \mathrm{uL}$ sterile water) was spread using a dampened sterile cotton swab over the rest of the surface area on the plate. After 7 days, the radius of the inhibitory zone was measured. Two replicates were performed for each pairing.

Activity-guided fractionation and isolation of nocamycin V. A dilute spore suspension of Amycolatopsis 17SM-2A was spread onto 19 YMEA agar plates $(60 \mathrm{~mL}$ agar per $150 \times 15 \mathrm{~mm}$ plate, $200 \mu \mathrm{L}$ spore suspension per plate), which were incubated at $30^{\circ} \mathrm{C}$ for 14 days. The agar was then cut into $1 \mathrm{~cm} \times 1 \mathrm{~cm}$ squares and soaked in EtOAc for approximately $18 \mathrm{~h}$. This extract was decanted, the agar was soaked in additional EtOAc for $4 \mathrm{~h}$, and the combined EtOAc portions were concentrated in vacuo and redissolved in $10 \mathrm{~mL} \mathrm{MeOH}$. The $\mathrm{MeOH}$-soluble extract was absorbed onto celite. The celite-adsorbed extract was dry-packed onto a $5 \mathrm{~g} \mathrm{C}_{18}$ SepPak column (Waters) that had been conditioned and pre-equilibrated with $20 \% \mathrm{MeCN}$ in $\mathrm{H}_{2} \mathrm{O}$ containing $0.1 \%$ formic acid. Fractions were collected during elution with a step gradient of $20 \%, 40 \%, 60 \%, 80 \%$, and $100 \% \mathrm{MeCN}$, all containing $0.1 \%$ formic acid. Two consecutive fractions from elution at $60 \%$ MeCN showed the most inhibition of Pseudonocardia 17SM-1. These active fractions were combined and subjected to semi-preparative reversed-phase HPLC (Phenomenex Kinetex $5 \mu \mathrm{m}$ Biphenyl $250 \mathrm{~mm} \times 10 \mathrm{~mm}$ column, $2.5 \mathrm{~mL} / \mathrm{min}$ ) at $35 \% \mathrm{MeCN}$ in $\mathrm{H}_{2} \mathrm{O}$ with $0.1 \%$ formic acid for 1 min followed by a gradient of $35 \%$ to $100 \% \mathrm{MeCN}$ in $\mathrm{H}_{2} \mathrm{O}$ containing $0.1 \%$ formic acid over 20 min. Fractions were collected and the HPLC fraction with greatest activity corresponded to 
nocamycin $\mathrm{V}$, which eluted at 13.1 minutes. Nocamycin $\mathrm{V}$ was isolated as an amorphous yellow solid in a yield of $8.9 \mathrm{mg}$.

Nocamycin V: $[\alpha]_{D^{23}}^{23} 54^{\circ}(\mathrm{EtOH}) ; \mathrm{UV}(\mathrm{EtOH}) \lambda_{\max } 253,288$, and $333 \mathrm{~nm}$; NMR spectral data, see Supporting Information, Table S2; HR-ESI-MS m/z 520.2180 [M+H+] (calcd for $\mathrm{C}_{26} \mathrm{H}_{34} \mathrm{NO}_{10}$, $520.2183, \Delta 0.6 \mathrm{ppm})$.

Genome sequencing. Using the Qiagen Gentra Puregene Yeast/Bact. kit, genomic DNA was isolated from pelleted cell mass from a culture of Amycolatopsis 17SM-2A grown in YMEA liquid media. Library preparation and sequencing by PacBio RS II (2 SMRT cells) was performed by the UC Riverside genomics core facility. De novo genome assembly was performed using HGAP 4 via the de novo genome assembly tool within the SMRT Analysis (v6) software package, which yielded a single contig. Additional polishing was carried out using the Resequencing tool within SMRT Analysis. The genome has been deposited in the GenBank database (accession number CP092497), and raw sequence data have been deposited in the Sequence Read Archive (accession number PRJNA808064).

Biosynthetic gene cluster annotation and analysis. Gene detection and annotation was performed using RAST v2.0. ${ }^{35}$ Biosynthetic gene cluster detection was conducted using antiSMASH v6.0. ${ }^{25}$ Open reading frames of less than 150 nucleotides were omitted from further analysis. The nocamycin $\mathrm{V}$ biosynthetic gene cluster was identified in additional genomes in GenBank through both the Cluster Blast feature within antiSMASH and a BlastP search of the Dieckmann cyclase NmvC from Amycolatopsis 17SM-2A against the nonredundant protein sequences database. Protein sequences for cytochromes P450 were aligned using MUSCLE and a maximum likelihood phylogeny was generated using PhyML v3.0 within Phylogeny.fr. ${ }^{36-38}$

LCMS Screen for nocamycin V. Bacterial isolates were grown on YMEA agar at $30^{\circ} \mathrm{C}$ for 14 days, after which the agar was cut into $1 \mathrm{~cm} \times 1 \mathrm{~cm}$ squares and soaked in EtOAc. These 
extracts were concentrated in vacuo and redissolved in $\mathrm{MeOH}$. The resulting extract solutions were subjected to LCMS analysis (Eclipse XDB-C18 $5 \mu \mathrm{m} 150 \mathrm{~mm}$ x $4.6 \mathrm{~mm}$ column, $1.0 \mathrm{~mL} / \mathrm{min}$ ) with a gradient of $10 \%$ acetonitrile in water with $0.1 \%$ TFA to $100 \%$ acetonitrile with $0.1 \%$ TFA over 8 minutes. Nocamycin $\mathrm{V}$ was observed at a retention time of 6.7 minutes.

Agar diffusion assays. Agar lawns were prepared by mixing an inoculum of test strain with soft YMEA agar $\left(4 \mathrm{~mL} ; 55^{\circ} \mathrm{C} ; 0.75 \%\right.$ agar). The mixture was poured on top of a plate of YMEA agar (25 mL per $100 \times 15$ mm dish) and left to solidify. Three evenly spaced holes were punched through both layers of agar using a sterilized metal punch ( $5 \mathrm{~mm}$ diameter). Two wells were loaded with a 10 ug solution of nocamycin $\mathrm{V}$ in $25 \mu \mathrm{L}$ of $1: 1 \mathrm{DMSO}$ and water. The third well was loaded with a $25 \mu \mathrm{L}$ of a control solution of $1: 1 \mathrm{DMSO}$ and water. The diameter of the zone of inhibition was monitored over several days and measured once growth stopped. The zones of inhibition for Amycolatopsis 17SM-2A and 17SM-8A were reported after 2 days. The zones of inhibition for Pseudonocardia 17SM-1 and Amycolatopsis 18SM-2A were reported after 5 days. The zones for Pseudonocardia 17SM-6 and PLR1 were reported after 6 days. The zones for Pseudonocardia 17SM-3, 17SE-9, 18PO-3, and 18AZ-4, and for E. coli, B. subtilis, S. cerevisiae and Escovopsis sp. were reported after 7 days. The average diameter taken from the two zones on the final day of zone growth was reported.

\section{ACKNOWLEDGMENTS}

This work was funded by Keck Science Department start-up funds and by an American Society of Pharmacognosy Research Starter Grant. We thank Michele Lanan for assistance securing permits and for supporting our collection work. 
Supporting Information: Summary of bacterial strains used; mass spectra, NMR spectra, and NMR spectral data for nocamycin V; summary of nocamycin V BGC genes; phylogeny of cytochromes P450 from tirandamycin and nocamycin BGCs; summary of all putative nocamycin V BGCs.

\section{REFERENCES}

(1) Currie, C. R. A Community of Ants, Fungi, and Bacteria: A Multilateral Approach to Studying Symbiosis. Annual Review of Microbiology 2001, 55 (1), 357-380. https://doi.org/10.1146/annurev.micro.55.1.357.

(2) Oh, D.-C.; Poulsen, M.; Currie, C. R.; Clardy, J. Dentigerumycin: A Bacterial Mediator of an Ant-Fungus Symbiosis. Nature Chemical Biology 2009, 5 (6), 391-393. https://doi.org/10.1038/nchembio.159.

(3) Van Arnam, E. B.; Ruzzini, A. C.; Sit, C. S.; Horn, H.; Pinto-Tomás, A. A.; Currie, C. R.; Clardy, J. Selvamicin, an Atypical Antifungal Polyene from Two Alternative Genomic Contexts. Proceedings of the National Academy of Sciences 2016, 113 (46), 1294012945. https://doi.org/10.1073/pnas.1613285113.

(4) Chevrette, M. G.; Carlson, C. M.; Ortega, H. E.; Thomas, C.; Ananiev, G. E.; Barns, K. J.; Book, A. J.; Cagnazzo, J.; Carlos, C.; Flanigan, W.; Grubbs, K. J.; Horn, H. A.; Hoffmann, F. M.; Klassen, J. L.; Knack, J. J.; Lewin, G. R.; McDonald, B. R.; Muller, L.; Melo, W. G. P.; Pinto-Tomás, A. A.; Schmitz, A.; Wendt-Pienkowski, E.; Wildman, S.; Zhao, M.; Zhang, F.; Bugni, T. S.; Andes, D. R.; Pupo, M. T.; Currie, C. R. The Antimicrobial Potential of Streptomyces from Insect Microbiomes. Nature Communications 2019, 10 (1), 516. https://doi.org/10.1038/s41467-019-08438-0.

(5) Currie, C. R.; Bot, A. N. M.; Boomsma, J. J. Experimental Evidence of a Tripartite Mutualism: Bacteria Protect Ant Fungus Gardens from Specialized Parasites. Oikos 2003, 101 (1), 91-102. https://doi.org/10.1034/j.1600-0706.2003.12036.x.

(6) Currie, C. R.; Poulsen, M.; Mendenhall, J.; Boomsma, J. J.; Billen, J. Coevolved Crypts and Exocrine Glands Support Mutualistic Bacteria in Fungus-Growing Ants. Science 2006, 311 (5757), 81-83. https://doi.org/10.1126/science.1119744.

(7) Steffan, S. A.; Chikaraishi, Y.; Currie, C. R.; Horn, H.; Gaines-Day, H. R.; Pauli, J. N.; Zalapa, J. E.; Ohkouchi, N. Microbes Are Trophic Analogs of Animals. Proceedings of the National Academy of Sciences 2015, 112 (49), 15119-15124. https://doi.org/10.1073/pnas.1508782112.

(8) Li, H.; Sosa-Calvo, J.; Horn, H. A.; Pupo, M. T.; Clardy, J.; Rabeling, C.; Schultz, T. R.; Currie, C. R. Convergent Evolution of Complex Structures for Ant-Bacterial Defensive Symbiosis in Fungus-Farming Ants. PNAS 2018, 115 (42), 10720-10725. https://doi.org/10.1073/pnas.1809332115.

(9) Poulsen, M.; Erhardt, D. P.; Molinaro, D. J.; Lin, T.-L.; Currie, C. R. Antagonistic Bacterial Interactions Help Shape Host-Symbiont Dynamics within the Fungus-Growing AntMicrobe Mutualism. PLoS ONE 2007, 2 (9), e960. https://doi.org/10.1371/journal.pone.0000960.

(10) Van Arnam, E. B.; Ruzzini, A. C.; Sit, C. S.; Currie, C. R.; Clardy, J. A Rebeccamycin Analog Provides Plasmid-Encoded Niche Defense. Journal of the American Chemical Society 2015, 137 (45), 14272-14274. https://doi.org/10.1021/jacs.5b09794. 
(11) Chang, P. T.; Rao, K.; Longo, L. O.; Lawton, E. S.; Scherer, G.; Van Arnam, E. B. Thiopeptide Defense by an Ant's Bacterial Symbiont. J. Nat. Prod. 2020, 83 (3), 725-729. https://doi.org/10.1021/acs.jnatprod.9b00897.

(12) Goldstein, S. L.; Klassen, J. L. Pseudonocardia Symbionts of Fungus-Growing Ants and the Evolution of Defensive Secondary Metabolism. Frontiers in Microbiology 2020, 11, 3341. https://doi.org/10.3389/fmicb.2020.621041.

(13) Scheuring, I.; Yu, D. W. How to Assemble a Beneficial Microbiome in Three Easy Steps. Ecology Letters 2012, 15 (11), 1300-1307. https://doi.org/10.1111/j.14610248.2012.01853.x.

(14) Worsley, S. F.; Innocent, T. M.; Holmes, N. A.; Al-Bassam, M. M.; Schiøtt, M.; Wilkinson, B.; Murrell, J. C.; Boomsma, J. J.; Yu, D. W.; Hutchings, M. I. Competition-Based Screening Helps to Secure the Evolutionary Stability of a Defensive Microbiome. BMC Biol 2021, 19 (1), 205. https://doi.org/10.1186/s12915-021-01142-w.

(15) Schultz, T. R.; Brady, S. G. Major Evolutionary Transitions in Ant Agriculture. Proceedings of the National Academy of Sciences 2008, 105 (14), 5435-5440. https://doi.org/10.1073/pnas.0711024105.

(16) Rabeling, C.; Cover, S. P.; Johnson, R. A.; Mueller, U. G. A Review of the North American Species of the Fungus-Gardening Ant Genus Trachymyrmex (Hymenoptera: Formicidae). Zootaxa 2007, 1664, 1-54.

(17) Schumacher, A.; Whitford, W. G. The Foraging Ecology of Two Species of Chihuahuan Desert Ants:Formica Perpilosa AndTrachyrmyrmex Smithi Neomexicanus (Hymenoptera Formicidae). Ins. Soc 1974, 21 (3), 317-330. https://doi.org/10.1007/BF02226923.

(18) Poulsen, M.; Cafaro, M.; Boomsma, J. J.; Currie, C. R. Specificity of the Mutualistic Association between Actinomycete Bacteria and Two Sympatric Species of Acromyrmex Leaf-Cutting Ants. Molecular Ecology 2005, 14 (11), 3597-3604. https://doi.org/10.1111/j.1365-294X.2005.02695.x.

(19) Mo, X.; Gui, C.; Wang, Q. Elucidation of a Carboxylate O-Methyltransferase NcmP in Nocamycin Biosynthetic Pathway. Bioorganic \& Medicinal Chemistry Letters 2017, 27 (18), 4431-4435. https://doi.org/10.1016/j.bmcl.2017.08.010.

(20) Zhen, X.; Gong, T.; Liu, F.; Zhang, P.-C.; Zhou, W.-Q.; Li, Y.; Zhu, P. A New Analogue of Echinomycin and a New Cyclic Dipeptide from a Marine-Derived Streptomyces Sp. LS298. Marine Drugs 2015, 13 (11), 6947-6961. https://doi.org/10.3390/md13116947.

(21) Royles, B. J. L. Naturally Occurring Tetramic Acids: Structure, Isolation, and Synthesis. Chem. Rev. 1995, 95 (6), 1981-2001. https://doi.org/10.1021/cr00038a009.

(22) Mo, X.; Li, Q.; Ju, J. Naturally Occurring Tetramic Acid Products: Isolation, Structure Elucidation and Biological Activity. RSC Adv. 2014, 4 (92), 50566-50593. https://doi.org/10.1039/C4RA09047K.

(23) Carlson, J. C.; Li, S.; Burr, D. A.; Sherman, D. H. Isolation and Characterization of Tirandamycins from a Marine-Derived Streptomyces Sp. J Nat Prod 2009, 72 (11), 20762079. https://doi.org/10.1021/np9005597.

(24) Yu, Z.; Vodanovic-Jankovic, S.; Ledeboer, N.; Huang, S.-X.; Rajski, S. R.; Kron, M.; Shen, B. Tirandamycins from Streptomyces Sp. 17944 Inhibiting the Parasite Brugia Malayi Asparagine TRNA Synthetase. Org. Lett. 2011, 13 (8), 2034-2037. https://doi.org/10.1021/ol200420u.

(25) Blin, K.; Shaw, S.; Kloosterman, A. M.; Charlop-Powers, Z.; van Wezel, G. P.; Medema, M. H.; Weber, T. AntiSMASH 6.0: Improving Cluster Detection and Comparison Capabilities. Nucleic Acids Research 2021, 49 (W1), W29-W35. https://doi.org/10.1093/nar/gkab335.

(26) Mo, X.; Shi, C.; Gui, C.; Zhang, Y.; Ju, J.; Wang, Q. Identification of Nocamycin Biosynthetic Gene Cluster from Saccharothrix Syringae NRRL B-16468 and Generation 
of New Nocamycin Derivatives by Manipulating Gene Cluster. Microbial Cell Factories 2017, 16 (1), 100. https://doi.org/10.1186/s12934-017-0718-5.

(27) Mo, X.; Zhang, H.; Du, F.; Yang, S. Short-Chain Dehydrogenase NcmD Is Responsible for the C-10 Oxidation of Nocamycin F in Nocamycin Biosynthesis. Front Microbiol 2020, 11, 610827. https://doi.org/10.3389/fmicb.2020.610827.

(28) Carlson, J. C.; Li, S.; Gunatilleke, S. S.; Anzai, Y.; Burr, D. A.; Podust, L. M.; Sherman, D. $\mathrm{H}$. Tirandamycin Biosynthesis Is Mediated by Co-Dependent Oxidative Enzymes. Nature Chemistry 2011, 3 (8), 628-633. https://doi.org/10.1038/nchem.1087.

(29) Newmister, S. A.; Srivastava, K. R.; Espinoza, R. V.; Caddell Haatveit, K.; Khatri, Y.; Martini, R. M.; Garcia-Borràs, M.; Podust, L. M.; Houk, K. N.; Sherman, David. H. Molecular Basis of Iterative C-H Oxidation by Taml, a Multifunctional P450 Monooxygenase from the Tirandamycin Biosynthetic Pathway. ACS Catal. 2020, 10 (22), 13445-13454. https://doi.org/10.1021/acscatal.0c03248.

(30) V. Espinoza, R.; Haatveit, K. C.; Grossman, S. W.; Tan, J. Y.; McGlade, C. A.; Khatri, Y.; Newmister, S. A.; Schmidt, J. J.; Garcia-Borràs, M.; Montgomery, J.; Houk, K. N.; Sherman, D. H. Engineering P450 Taml as an Iterative Biocatalyst for Selective LateStage C-H Functionalization and Epoxidation of Tirandamycin Antibiotics. ACS Catal. 2021, 11 (13), 8304-8316. https://doi.org/10.1021/acscatal.1c01460.

(31) Jiang, M.; Chen, S.; Li, J.; Liu, L. The Biological and Chemical Diversity of Tetramic Acid Compounds from Marine-Derived Microorganisms. Mar Drugs 2020, 18 (2), 114. https://doi.org/10.3390/md18020114.

(32) Santamaría, R. I.; Martínez-Carrasco, A.; Sánchez de la Nieta, R.; Torres-Vila, L. M.; Bonal, R.; Martín, J.; Tormo, R.; Reyes, F.; Genilloud, O.; Díaz, M. Characterization of Actinomycetes Strains Isolated from the Intestinal Tract and Feces of the Larvae of the Longhorn Beetle Cerambyx Welensii. Microorganisms 2020, 8 (12), 2013. https://doi.org/10.3390/microorganisms8122013.

(33) Tsukiura, H.; Tomita, K.; Hanada, M.; Kobaru, S.; Tsunakawa, M.; Fujisawa, K.; Kawaguchi, H. Bu-2313, a New Antibiotic Complex Active against Anaerobes. I. Production, Isolation and Properties of Bu-2313 A and B. J. Antibiot. 1980, 33 (2), 157165.

(34) Horváth, G.; Brazhnikova, M.; Konstantinova, N.; Tolstykh, I.; Potapova, N. The Structure of Nocamycin, a New Antitumor Antibiotic. The Journal of Antibiotics 1979, 32 (6), 555558.

(35) Aziz, R. K.; Bartels, D.; Best, A. A.; DeJongh, M.; Disz, T.; Edwards, R. A.; Formsma, K.; Gerdes, S.; Glass, E. M.; Kubal, M.; Meyer, F.; Olsen, G. J.; Olson, R.; Osterman, A. L.; Overbeek, R. A.; McNeil, L. K.; Paarmann, D.; Paczian, T.; Parrello, B.; Pusch, G. D.; Reich, C.; Stevens, R.; Vassieva, O.; Vonstein, V.; Wilke, A.; Zagnitko, O. The RAST Server: Rapid Annotations Using Subsystems Technology. BMC Genomics 2008, 9 (1), 75. https://doi.org/10.1186/1471-2164-9-75.

(36) Edgar, R. C. MUSCLE: Multiple Sequence Alignment with High Accuracy and High Throughput. Nucleic Acids Res. 2004, 32 (5), 1792-1797. https://doi.org/10.1093/nar/gkh340.

(37) Guindon, S.; Dufayard, J.-F.; Lefort, V.; Anisimova, M.; Hordijk, W.; Gascuel, O. New Algorithms and Methods to Estimate Maximum-Likelihood Phylogenies: Assessing the Performance of PhyML 3.0. Systematic Biology 2010, 59 (3), 307-321. https://doi.org/10.1093/sysbio/syq010.

(38) Dereeper, A.; Guignon, V.; Blanc, G.; Audic, S.; Buffet, S.; Chevenet, F.; Dufayard, J.-F.; Guindon, S.; Lefort, V.; Lescot, M.; Claverie, J.-M.; Gascuel, O. Phylogeny.Fr: Robust Phylogenetic Analysis for the Non-Specialist. Nucleic Acids Research 2008, 36 (Web Server), W465-W469. https://doi.org/10.1093/nar/gkn180. 
TOC graphic:

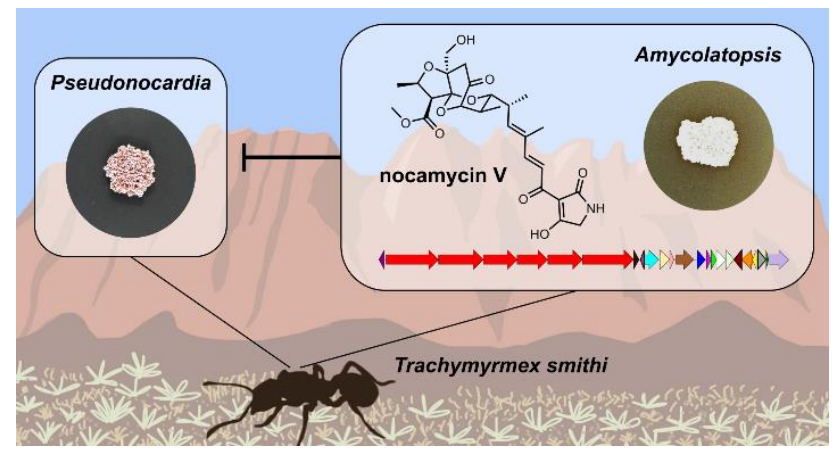

